\title{
Social Capital and Tourism Development: Insights from a Peripheral Destination
}

\author{
Easnin Ara $^{1} \quad$ Muhammad Shoeb-Ur-Rahman ${ }^{2 *} \quad$ Silvi Azad ${ }^{3}$ \\ 1.Assistant Professor, Department of Business Administration in Marketing, Faculty of Business Studies, \\ Bangladesh University of Professionals, Mirpur Cantonment, Dhaka 1216, Bangladesh \\ 2.Associate Professor, Department of Tourism and Hospitality Management, Faculty of Business Studies, \\ University of Dhaka, Dhaka 1000, Bangladesh \\ 3.Postgraduate Student, Department of Tourism and Hospitality Management, Faculty of Business Studies, \\ University of Dhaka, Dhaka 1000, Bangladesh
}

\begin{abstract}
There has been a growing emphasis on understanding the nexus between tourism and social capital from different contexts. This study aims to develop an in-depth understanding of the influence of social capital on tourism development from a peripheral destination context of the Sundarbans, Bangladesh. In this vein, a qualitative case study approach was adopted to gather empirical evidence primarily through qualitative semi-structured interviews with relevant stakeholders. Thematic analysis was adopted to interpret the gathered data. Findings of the study reflect that bridging and linking capitals play a critical role in community-involved tourism development in the Sundarbans. Furthermore, the study reveals that the absence of trust and misuse of power can threaten tourism development in the observed context. This study contributes to the broader literature of tourism-social capital nexus and extends our current understanding in reference to a developing country's peripheral destinations.
\end{abstract}

Keywords: Social capital, peripheral destination, linking capital, the Sundarbans, Bangladesh

DOI: 10.7176/EJBM/13-22-09

Publication date: November $30^{\text {th }} 2021$

\section{Introduction}

Generally understood as the connections among individuals or groups, the concept of social capital permeates various structural and cognitive features (networks, norms and values, trust, etc.) that influence horizontal and vertical cooperation (Castiglione et al., 2008; OECD, 2001; Putman, 2000). Social capital has been considered as an important inclusion to analyze social impacts in tourism destinations (Moscardo, 2012; Mura \& Tabakoli, 2014; Ooi et al., 2015; Rahman et al., 2021). In that, the presence of strong social capital is believed to facilitate cooperation in actualizing opportunities while weak social capital is supposed to instigate conflicts among destination communities. Thus, social capital becomes a useful metaphor to explain and manifest development phenomena at a local or destination level (Jóhannesson et al., 2003). Within the growing consideration for social aspects in tourism, social capital has been emphasized with a call for understanding from different contexts, especially from non-western contexts (Mura \& Tabakoli, 2014; Moscardo et al., 2017; Rahman et al., 2021).

Responding to the above call, this paper aims to develop an in-depth understanding of the nexus between social capital and tourism development particularly in the context of a peripheral destination, namely the Sundarbans, in Bangladesh. The rural features and geographical remoteness along with poor infrastructure and amenities have characterized Sundarbans as a peripheral destination (Hohl \& Tisdell, 1995). The Sundarbans Reserve Forests (SRF) is the largest mangrove forest in the world and remains one of the most popular tourism destinations in Bangladesh, which has been broadly featured for community-involved ecotourism development (Hoque et al., 2018). Regardless of the growing popularity of community centered tourism initiatives (in this region), little has been explored in terms of social aspects of such tourism development, particularly emphasizing social capital.

Accordingly, this study comprehends tourism development and social capital nexus at the community level in a peripheral destination such as the Sundarbans. In this regard, we define community as "the people who live and work within a geographical region being promoted as a tourism destination" (Moscardo et al., 2017, p. 287).

\section{Social capital and tourism development nexus}

The concept of social capital has gained popularity through the works of Bourdieu (1986), Coleman (1988) and Putnam (2000). Putnam (2000, p.19) defines social capital as “... connections among individuals - social networks and the norms of reciprocity and trustworthiness that arise from them." Accordingly, the core elements of social capital include social networks, trust, norms and values, and relationships facilitating access to resources (Bourdieu, 1986; Coleman, 1988; Castiglione et al., 2008; OECD, 2001; Putnam, 2000). These elements can be understood via 'structural' and 'cognitive' features, and can be scoped at various levels of observation unit such as micro (i.e., individual), meso (i.e., community), and macro (i.e., regional or national) (Castiglione et al., 2008). While social networks refer to the structural (objective in nature) aspect of social capital, trust and norms represent the cognitive 
(subjective and intangible) features (Rahman et al., 2021). Both the elements and features of social capital are generalized by using three distinct descriptors: bonding, bridging, and linking social capital (Putnam, 2000; Woolcock, 2000). Bonding social capital is inward-looking in nature due to its focus on relationships exclusively within a group with homogenous characteristics (KC et al., 2018) whereas bridging social capital reflects on relationships among different groups of people (Ooi et al., 2015; Putnam, 2000). Linking social capital is outwardlooking and extends the essence of bridging social capital by emphasizing heterogeneous ties reflecting vertical associations to the people who hold the right to and/or allocate resources (Poortinga, 2012).

While social capital is not a new concept, it has received attention from the tourism researchers since 2000s (Jóhannesson et al., 2003; Jones, 2005; Macbeth et al., 2004; Karlsson, 2005; Nordin \& Westlund, 2009) and got momentum eventually throughout the last decade (KC et al., 2018; Moscardo et al., 2017; Mura \& Tavakoli, 2014; Rahman et al., 2021; Soulard et al., 2018; Zhao et al., 2011). In general, literature reveals that tourism development initiatives and tourism experiences are supported by the evidence of strong social capital ensuring host community involvement and participation (Moscardo, 2014; Mura \& Tavakoli, 2014; Nordin \& Westlund, 2009; Park et al., 2012). For instance, social capital appears to play an important role in fostering tourism businesses and entrepreneurships for the local communities (Karlsson, 2005; Zhao et al., 2011).

The role of various elements as well as structural and cognitive features of social capital may vary to create impact at a given level of observation. It has been argued that tourism can enhance bonding social capital by strengthening the sense of community cohesion, allowing higher social interactions within the community members (McGehee et al., 2015). Tourism development can equally contribute to bridging and linking social capitals by connecting different groups in different ways (KC et al., 2018; Moscardo, 2012). Zhao et al. (2011) in the context of China show that the structural features of social capital (i.e., social networks) are highly influential in fostering both the ability and probability of individuals to establish tourism businesses, while cognitive aspects play a minor role. Conversely, highlighting the importance of cognitive elements (e.g., trust, values and norms of reciprocity) Jones (2005) claims that trust and norms of reciprocity ensure a high level of community participation in tourism. Henceforth, it can be argued that both the structural and cognitive elements of social capital enhance the willingness of community participation building network(s), within and/or across communities or social groups, for their mutual benefits through tourism development initiatives (Hwang \& Stewart, 2017; McGehee et al., 2010; Sanyal \& Routray, 2016).

However, inequitable distribution of benefits among the destination communities may badly impact upon various elements of social capital such as trust especially in 'peripheral destinations' and destinations with diverse ethnic communities (Moscardo et al., 2017; Rahman et al., 2021). A peripheral destination is often characterized by rural and geographical remoteness, weak social resilience, poor infrastructure and amenities, dependence on traditional industries, and limited community capacity to influence decision-making (Hohl \& Tisdell, 1995; Moscardo, 2005).

While the extant literature seemingly evidenced a reciprocal relation between tourism (development) and social capital, this study aims to understand and reconfirm the relationship in the context of a peripheral destination in Bangladesh. On this note, identified elements, features and descriptors of social capital form the analytical base of our study.

\section{Methods}

\subsection{Research setting}

This study explores the research issue within a broader research setting of the Sundarbans, which remains the world's largest Mangrove forest. In view of the rich biodiversity and the label of World Heritage Site as declared by UNESCO in 1997, the Sundarbans has received growing attention both from the domestic and foreign tourists (Hoque et al., 2018; Iftekhar \& Islam, 2004). Given the current research focus, resident communities from two distant locations within the Khulna administrative range were targeted. First, communities living near Jamtola beach in Kotka; second, communities from Sreerampur, Koyra Upazilla. The inclusion of these locations is evidenced by the prospect of tourism activities and tourists' attractions (Alam et al., 2010; Hoque et al., 2018). In tourism studies, communities encapsulate a geographic dimension indicating the locale, where tourism happens (Mowforth \& Munt, 2015). Together with a geographic view, this study upholds the essence of mutual interests, shared cultural values, and professional linkages to frame the notion of 'community' (Joppe, 1996; Telfer \& Sharpley, 2015). Within the scope of such a frame, research participants are thus categorized as local residents, fishermen, woodcutters, honey collectors, etc.

\subsection{Data collection}

Within a single embedded case study (Yin, 2014), we collected data covering two time periods. First phase of data was collected from December 2018 to February 2019 and the second phase covers August 2019 to September 2019. This study has utilized semi structured interview techniques as the primary method of data collection. The qualitative interview was preferred over other conventional methods such as questionnaire survey since it provides 
rich information while allowing participants to narrate events that eventually link theoretical constructs (Yin, 2014; Rahman, 2019). In total, seventeen participants were interviewed with an average duration of 50 minutes each. The participants represent the key stakeholder categories of local resident, fisherman, honey collector, woodcutter, and institutional representatives such as forest department officials. The institutional representatives were sought out purposefully to evaluate the linking capital. The profile and coverage of research participants are shown in Table 1.

Table 1. Summary of research participants.

\begin{tabular}{|l|l|c|}
\hline Category & Interview code & Number (n) \\
\hline Local resident & $\begin{array}{l}\text { interview no. 1, 2, 3, 4, 6, 16, } \\
17\end{array}$ & 07 \\
\hline Fisherman & interview no. 7, 9, 10 & 03 \\
\hline Honey collector & interview no. 8, 11 & 02 \\
\hline Woodcutter department & interview no. 5, 13 & 02 \\
\hline $\begin{array}{l}\text { Forest } \\
\text { representatives }\end{array}$ & interview no. 12, 14, 15 & 03 \\
\hline \multicolumn{2}{|r|}{ Total (N) } & 17 \\
\hline
\end{tabular}

Stratified purposeful sampling complemented by snowball sampling techniques have governed the selection of participants in this study (Patton, 2002). Contextual familiarity of the authors has facilitated the selection of initial stratum and the participants, which later was followed by chain referrals until we observed 'data saturation' indicating repetitive information coming from the informants.

\subsection{Data analysis}

The collected qualitative data have undergone a rigorous thematic analysis process (Braun \& Clark, 2006). Since the interviews were conducted in Bengali, the interviews were translated into English after transcription. To keep the meaning intact, we get the translated files checked by a University Professor in English while confirming the anonymity of the research participants. The implicit and explicit meanings from the interview dataset have been explored via the cyclic act of coding (Saldaña, 2016). Afterward, the emergent 'themes' were identified encapsulating the codes being explored, which were refined into a coherent narrative to inform the research objective and were reported subsequently (Braun \& Clarke, 2006; Saldaña, 2016).

\section{Findings}

Our analysis reveals that tourism development initiatives within the research setting require attention to detail to the social capital elements including social networks, norms of reciprocity, and trust.

Alongside the habitat of numerous wildlife and a reservoir of distinguished flora and fauna, Sundarbans hosts several communities (e.g., in terms of occupation, religious beliefs) who have different values and professional orientations. In general, the community people were found to respect each other's values and norms, which essentially forms the basis of strong social networks. For instance, one local resident (interview no. 2) from the Jamtola beach in Kotka stated that:

... We believe in the God 'Manasa' (the goddess of snake) and the people who cut trees and collect honey believe in the God 'Bonbibi' (the lady of the forest) .. . We have differences in our cultural orientations; still we attend the festivals of each other and celebrate occasions together.

Such a view was equally echoed in the observations of two more participants, one honey collector and one woodcutter (interview no. 8 and 13), indicating a spontaneous sharing of values facilitates a good tie across different communities. This sharing is believed to contribute positively to the structural bridging that may shape the overall tourism experience. On this note, comment from one local resident (interview no. 1) who frequently performs as a local tour guide is noteworthy:

From my personal experience, I know some community people who are directly or indirectly involved in tourism activities. I meet tourists of differing needs or requirements. For example, a few days back I met a tourist who wanted to experience honey collection; although it was a bit risky, still I managed through my personal networks. The tourist did not require to pay any extra amount except buying honey directly from the honey collector. The honey collector benefitted by receiving a fair amount by not losing to a middleman.

The above quote reflects the connections and/or networking among different stakeholders as the enabling factor for tourism development while ensuring benefits for the actors involved. As seen, it helps the local people to get an earning by serving tourists and tourists also benefit from having a memorable and distinct experience. This was also confirmed by several research participants (interview no. 4, 5, 7, 9 and 16).

In a peripheral region such as the Sundarbans, a feeling of insecurity brings together different professionals (communities) and thereby strengthens connection and bondage among communities. For example, one participant (interview no. 5) said that "Living near the forest is not easy. Often, we have to face wild animals such as the 
Royal Bengal Tiger. When we go to the forest (to cut wood) we stay closer to a group of more than 20 people including woodcutters, boatmen, and honey collectors." This observation indicates that the presence of strong bridging capital results in a peripheral region as a natural outcome of protection and survival needs.

Together with social networks, a high level of norm of reciprocity was reportedly contributing towards favorable bridging capital. A participant (interview no. 11) who was a honey collector (from Jamtola, Kotka) mentioned that "... I bought wood from my neighbor (a woodcutter) at a very marginal price while repairing my home. In return, I sold honey to him at a reduced rate. This is quite a common practice here and this is how we live here." Both the embedded units have evidenced similar findings. Another participant (interview no. 17) from Sreerampur narrated a situation where he experienced a boat's engine break out in the middle of a river and was rescued immediately by another boatman without any charge; there were tourists in the boat who praised such a gesture. The communal cohesion and cooperative nature of the community people are seen as a facilitating factor to promote and develop tourism in the Sundarbans.

On the one hand, such a congenial response from one community member helps another to get a solution for the emergency incurred. On the other hand, it provides visitors a sense of assurance that in any emergency situation they will get help from the community people followed by their good relationship and cooperative mindsets. These norms of reciprocity - both within and across the communities - have been playing an important role in the community members' involvement in tourism and also increasing the tourists' interest to visit the region. This was reconfirmed in the observation of a forest Department's official (interview no. 12) who claimed that:

I have been working here for five years. I have heard many complaints from visitors that they find the wild monkeys very annoying, especially snatching food all of a sudden and throwing things targeting them. However, they [tourists] appreciate cooperation from the community people, I mean those who live nearby the forest, to get rid of those monkeys.

A final element of 'trust' has been reported as a key catalyst for understanding social capital and tourism development nexus. In general, trust issues were described by the research participants variably in line with the descriptors of social capital. In that, a good bonding and favorable bridging capital were evidenced while linking capital received mixed responses. All the participants argued that they maintain good intra and inter community relationships in which they rely on each other and they believe strongly that they will receive cooperation from community members as and when required.

However, participants from local resident, woodcutter, and honey collector categories (interview no. 3, 4, 5, and 8) stated that they lack cooperation from the forest department's officials. On one occasion, one participant (interview no. 8) claimed that "... they (indicating forest department officials) sometimes ask for honey from me without any payment." When discussing such a claim with one forest department's representative (interview no. 15), the representative argued in a way that "I am not sure how it happens and who did that. Anyway, if that really happens, it is quite unfortunate. Due to the government's instructions, we have to restrict movement to the jungle sometimes, which might create dissatisfaction among the professionals." These conversations clearly indicate that the level of trust is not conducive between the resource allocation authority and community people.

Alongside, lack of trust has been also reported in assessing the relationship between community people and elected leaders who hold the authority to allocate resources. The communities need to rely on the leaders in terms of their liaison with the external entities or facilitators (e.g. government bodies, NGOs). Most of the local residents expressed their dissatisfaction with the community leaders in terms of their roles associated with tourism. Acknowledging such an issue, a forest department's representative (interview no. 14) stated that "The leaders dominate the community people. The community becomes deprived of their demand and what they deserve. The community people do not trust the leaders fully. This is a hindrance for tourism development." Thus, a weak linking capital has been evidenced, which in turn is seen as an obstacle to developing tourism in a peripheral region such as the Sundarbans.

\section{Discussion and conclusion}

The critical interfaces of social capital elements provide a valuable theoretical lens to understand the nexus between social capital and tourism development in a peripheral destination. In such a destination, communities remain vulnerable to their existence and sustenance, which brings them closer and strengthens their social network. This sort of horizontal ties can play a positive role in developing community-based tourism. As such, strong social capital upholds a sense of community and enhances cooperation within and across the communities at a destination (Jeong et al., 2006; Moscardo, 2014; Ooi et al., 2015).

Apart from the structural features of social networks, two cognitive features including social capital' elements of norm of reciprocity and trust bear utmost significance in shaping inclusive tourism experiences. A community with a high norm of reciprocity can more efficiently restrain opportunism and resolve problems through collective action (Keefer \& Knack, 2005; Grootaert \& van Bastelaer, 2002). This can further lead to effective participation in community activities and contribute to collective decision making at community level, which ultimately fosters equitable sharing of benefits. Equitable benefits sharing in turn can strengthen the level of trust (Rahman et al., 
2021). However, the level of trust is highly influenced by the power dynamics in which people with the authority to allocate resources hardly satisfy community people in general. In specific terms, a poor linking capital may tarnish the effectiveness of strong bridging and bonding capitals towards the development of tourism. This is particularly a fact that requires attention of tourism resource governance researchers as well as tourism policymakers.

This study reconfirms and extends current understanding of the tourism-social capital nexus from a unique context in Bangladesh. The interdependence of social capital elements vis-à-vis structural and cognitive features recalls the attention of policymakers to develop tourism (in peripheral regions) by emphasizing the strengths and minimizing the weaknesses of social capital. Further research can be conducted to understand and examine the horizontal and vertical ties by using different analytical approaches such as social network analysis. Moreover, by taking similar cases from different settings and comparing the results, future studies may explore underlying patterns and dimensions of social capital influencing the overall tourism development process.

\section{References}

Alam, M., Furukawa, Y., \& Akter, S. (2010). Forest-based tourism in Bangladesh: Status, problems, and prospects. Tourismos: An International Multidisciplinary Journal of Tourism, 5(1), 163-172.

Bourdieu, P. (1986). The forms of capital. In J. Richardson (Ed.), Handbook of theory and research for the sociology of education (pp. 241-258). New York: Greenwood Press.

Braun, V., \& Clarke, V. (2006). Using thematic analysis in psychology. Qualitative Research in Psychology, 3(2), $77-101$.

Castiglione, D., Van Deth, J. W., \& Wolleb, G. (Eds.). (2008). The handbook of social capital. Oxford University Press Inc.

Coleman, J. S. (1988). Social capital in the creation of human capital. American Journal of Sociology, 94, 95-120.

Grootaert, C., van Bastelaer, T., 2002. Understanding and measuring social capital: A multi-disciplinary tool for practitioners. Washington DC: The World Bank.

Hohl, A. E., \& Tisdell, C.A. (1995). Peripheral tourism: Development and management. Annals of Tourism Research, 22(3), 517-534.

Hoque, M. A., Ara, E., \& Rahman, M. S-. U-. (2018). Forest-based tourism in Bangladesh: Challenges unveiled for the Sundarbans. European Journal of Business and Management, 10(36), 97-107.

Hwang, D., \& Stewart, W. P. (2017). Social capital and collective action in rural tourism. Journal of Travel Research, 56(1), 81-93.

Iftekhar, M., \& Islam, M. (2004). Managing mangroves in Bangladesh: A strategy analysis. Journal of Coastal Conservation, 10(1-2), 139-146.

Jeong, K.-H., Sim, J.-M., \& Choi, K.-H. (2006). A study on the relationship between social capital and rural development in Korea. Research report no. R527. Seoul: Korea Rural Economic Institute.

Jóhannesson, G. P., Skaptadóttir, U. D., \& Benediktsson, K. (2003). Coping with social capital? The cultural economy of tourism in the north. Sociologia Ruralis, 43(1), 3-16.

Jones, S. (2005). Community-based ecotourism: The significance of social capital. Annals of Tourism Research, $32(2), 303-324$

Joppe, M. (1996). Sustainable community tourism development revisited. Tourism Management, 17(7), 475-479.

Karlsson, S.-E. (2005). The social and the cultural capital of a place and their influence on the production of tourism: a theoretical reflection based on an illustrative case study. Scandinavian Journal of Hospitality and Tourism, 5(2), 102-115.

Keefer, P., \& Knack, S. (2005). Social Capital, Social Norms and the New Institutional Economics. In C. M'enard and M. M. Shirley (eds.), Handbook of New Institutional Economics, (pp. 701-725). Netherlands: Springer.

KC, B., Morais. D. B., Seekamp, E., Smith, J. W., \& Peterson, M. N. (2018). Bonding and bridging forms of social capital in wildlife tourism microentrepreneurship: An application of social network analysis. Sustainability, 10, 315. http://dx.doi.org/10.3390/su10020315

Macbeth, J., Carson, D., \& Northcote, J. (2004). Social capital, tourism and regional development: SPCC as a basis for innovation and sustainability. Current Issues in Tourism, 7(6), 502-522. https://doi.org/10.1080/1368350050408668200

McGehee, N. G., Lee, S., O’Bannon, T., \& Perdue, R. (2010). Tourism-related social capital and its relationship with other forms of capital: An exploratory study. Journal of Travel Research, 49, 486-500.

McGehee, N. G., Knollenberg, W. \& Komorowski, A. (2015). The central role of leadership in rural tourism development: a theoretical framework and case studies, Journal of Sustainable Tourism, 1- 21. http://dx.doi.org/10.1080/09669582.2015.1019514

Moscardo, G. (2005). Peripheral tourism development: Challenges, issues and success factors. Tourism Recreation Research, 30(1), 27-43. http://dx.doi.org/10.1080/02508281.2005.11081231

Moscardo, G. (2012). Building social capital to enhance the quality of life of destination residents. In M. Uysal, 
R. Perdue, \& M. J. Sirgy (Eds.). Handbook of tourism and quality of life research (pp. 402-421). NY: Springer. Moscardo, G. (2014). Tourism and community leadership in rural regions: Linking mobility, entrepreneurship, tourism development and community well-being. Tourism Planning \& Development, 11(3), 354-370.

Moscardo, G., Konovalov, E., Murphy, L., McGehee, N., \& Schurmann, A. (2017). Linking tourism to social capital in destination communities. Journal of Destination Marketing \& Management, 6(4), 286-295.

Mowforth, M., \& Munt, I. (2015). Tourism and sustainability: Development, globalisation and new tourism in the third world. Abingdon, Oxon: Routledge.

Mura, P. \& Tavakoli, R. (2014). Tourism and social capital in Malaysia. Current Issues in Tourism, 17(1), 28-45.

Nordin, S., \& Westlund, H. (2009). Social capital and the life cycle model: The transformation of the destination Are. Tourism Review, 57(3), 259-284.

Ooi, N., Laing, J., \& Mair, J. (2015). Social capital as a heuristic device to explore sociocultural sustainability: a case study of mountain resort tourism in the community of Steamboat Springs, Colorado, USA. Journal of Sustainable Tourism, 23(3), 417-436.

OECD. (2001). The well-being of nations: The role of human and social capital. Paris: OECD.

Park, Duk-Byeong., Lee, Kwang-Woo., Choi, Hyun-Suk, \&, Yoon, Y. (2012). Factors influencing social capital in rural tourism communities in South Korea. Tourism Management, 33, 1511-1520.

Patton, M. Q. (2002). Qualitative research and evaluation methods (3rd ed.). Thousand Oaks, CA: Sage Publications.

Poortinga, W. (2012). Community resilience and health: The role of bonding, bridging, and linking aspects of social capital. Health \& Place, 18(2), 286-295.

Putnam, R. D. (1995). Bowling alone: America's declining social capital. Journal of Democracy, 6(1), 65 -78.

Putnam, R. D. (2000). Bowling alone: The collapse and revival of American community. NY: Simon and Schuster.

Rahman, M. S-. U-., (2019). Co-management for Tourism Development and Community Wellbeing: The Case of Hill Tracts, Bangladesh. Unpublished $\mathrm{PhD}$ thesis, Lincoln University, New Zealand.

Rahman, M. S-. U-, Simmons, D., Shone, M. C., \& Ratna, N. N. (2021): Social and cultural capitals in tourism resource governance: the essential lenses for community focused co-management. Journal of Sustainable Tourism, http://dx.doi.org/10.1080/09669582.2021.1903016

Saldaña, J. (2016). The coding manual for qualitative researchers. Los Angeles: SAGE.

Sanyal, S., \& Routray, J. K. (2016). Social capital for disaster risk reduction and management with empirical evidences from Sundarbans of India. International Journal of Disaster Risk Reduction, 19, 101-111.

Soulard, J., Knollenberg, W., Boley, B. B., Perdue, R. R., \& McGehee, N. G. (2018). Social capital and destination strategic planning. Tourism Management, 69, 189-200. https://doi.org/10.1016/j.tourman.2018.06.011

Telfer, D. J., \& Sharpley, R. (2015). Tourism and development in the developing world. London: Routledge.

Woolcock, M. (2000). Why should we care about social capital? Canberra Bulletin of Public Administration, 98, 17-19.

Yin, R. (2014). Case study research: Design and methods (5 $5^{\text {th }}$ ed.). Thousand Oaks, CA: Sage.

Zhao, W., Ritchie, B., \& Echtner, C., (2011). Social capital and tourism entrepreneurship. Annals of Tourism Research, 38(4), 1570-1593. 